\title{
A Factorial Design to Numerically Study the Effects of Brake Pad Properties on Friction and Wear Emissions
}

\author{
Jens Wahlström \\ KTH Royal Institute of Technology, Machine Design, 10044 Stockholm, Sweden \\ Correspondence should be addressed to Jens Wahlström; jensw@kth.se
}

Received 29 August 2016; Revised 11 October 2016; Accepted 12 October 2016

Academic Editor: Meng Hua

Copyright (C) 2016 Jens Wahlström. This is an open access article distributed under the Creative Commons Attribution License, which permits unrestricted use, distribution, and reproduction in any medium, provided the original work is properly cited.

\begin{abstract}
Airborne particulate emissions originating from the wear of pads and rotors of disc brakes contribute up to $50 \%$ of the total road emissions in Europe. The wear process that takes place on a mesoscopic length scale in the contact interfaces between the pads and rotors can be explained by the creation and destruction of contact plateaus. Due to this complex contact situation, it is hard to predict how changes in the wear and material parameters of the pad friction material will affect the friction and wear emissions. This paper reports on an investigation of the effect of different parameters of the pad friction material on the coefficient of friction and wear emissions. A full factorial design is developed using a simplified version of a previously developed cellular automaton approach to investigate the effect of four factors on the coefficient of friction and wear emission. The simulated result indicates that a stable third body, a high specific wear, and a relatively high amount of metal fibres yield a high and stable mean coefficient of friction, while a stable third body, a low specific wear, a stable resin, and a relatively high amount of metal fibres give low wear emissions.
\end{abstract}

\section{Introduction}

Up to $80 \%$ of the total road transport $\mathrm{PM}_{10}$ emissions are not exhaust-related but originate from tyre, road, and brake wear [1-3]. $\mathrm{PM}_{10}$ emissions from disc brakes contribute up to $50 \%$ of the total nonexhaust emissions according to Harrison et al. [4]. The $\mathrm{PM}_{10}$ emissions from disc brakes originate from the wear of pads and rotors.

There are two conformal sliding contacts between the pads and rotor in a disc brake. During a brake event, the pads are pushed into contact with the moving rotor and the resulting frictional force slows the vehicle. When the pads are in contact with the rotor, both contact surfaces will wear. A part of the total wear will become airborne as particulate emissions. The wear process that takes place in the contact interface between the pads and rotor can be explained on a mesoscopic scale (see, e.g., $[5,6])$. In this model, metal fibres or hard particles in the pad friction material form stable primary plateaus. Some wear particles can flow between the primary plateaus and some will build up against the primary plateaus and create secondary plateaus. The formation of secondary plateaus will increase the contact area and thus decrease the contact pressure.

To be able to design low emission brake systems, it is important to have simulation tools that take into account the plateau dynamics (the destruction and creation of contact plateaus/patches) in the interface between the pads and rotors on a mesoscopic length scale. Müller and Ostermeyer [7] developed a cellular automaton (CA) approach to simulate the plateau dynamics on a mesoscopic length scale. Inspired by this idea, Wahlström et al. [8-10] have developed a CA approach on a mesoscopic length scale that can be used to simulate macroscopic wear, friction, and wear emissions for a number of brake events. A comparison with tests conducted with an inertia dynamometer bench shows a promising qualitative correlation between the simulated and experimentally measured friction and wear behaviour.

The coefficient of friction (COF) and wear emissions depend on a number of parameters. It is therefore hard to foresee how changes in these parameters will affect the COF and wear emissions. This paper will therefore investigate the effect of different wear parameters of the pad friction material 


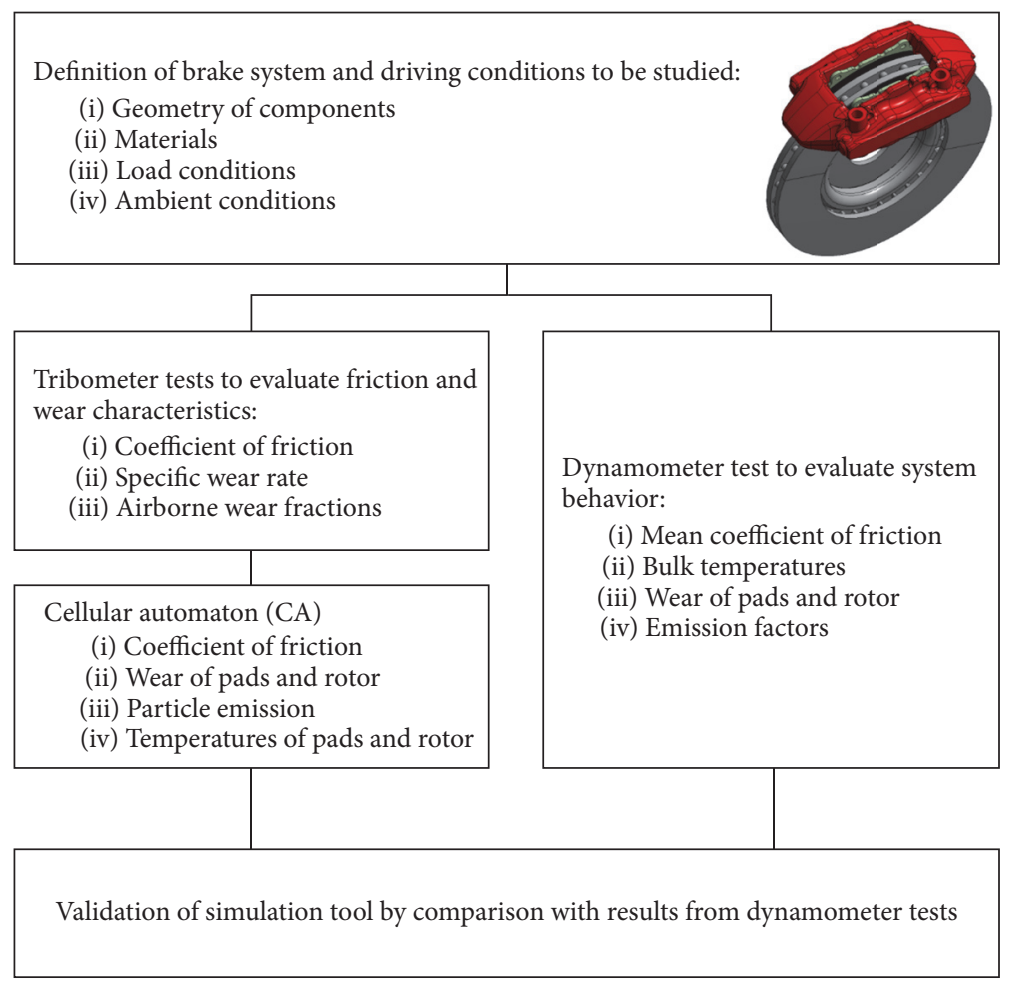

FIGURE 1: An overview of the simulation methodology.

on the COF and wear emissions using a full factorial design conducted with the CA approach.

\section{Simulation Methodology}

Based on the finite element analysis approach proposed by Wahlström et al. [11], Wahlström [8] presented a methodology to simulate friction, wear, and wear emissions from disc brakes. An overview of this simulation approach with its validation procedure can be seen in Figure 1.

In this methodology first the brake system and the driving conditions are defined, and thereafter the geometry and material data of the components, braking torque, and deceleration are set. These data are required to set the running conditions of the tribometer and dynamometer tests and as input data to the CA approach. The local COF, specific wear rate, and airborne wear fraction at different contact pressures and sliding speeds are determined by experiments in a modified POD designed for particle emission measurements [12]. These measures are used as input parameters in a CA approach [8-10] on a mesoscopic length scale that takes into account the plateau dynamics. To validate the simulation methodology, the simulated COF, wear profiles of pads and rotor, particle emissions, and the temperatures of the pad and rotor are compared to experimental measurements from an inertia brake dynamometer [13] designed for particle emission measurements.

The long-term goal of the simulation approach is to develop a design tool that uses input data from simple POD tests to estimate the friction and wear performance of novel pad material designs before going further and conducting relatively more complicated and expensive inertia dynamometer bench and field tests. However, this paper will focus only on a simplified version of the CA approach.

\section{Simplified Cellular Automaton Approach}

The principle of Wahlström's [8] CA method is to keep track of how much wear material is used to build up secondary plateaus and how much leaves the contact. The part that leaves the contact is defined as wear emissions in this paper. In brief, the calculation starts by first determining the contact pressures using a simple elastic foundation model. Then the COF is calculated as a decreasing linear function of the local contact pressures. The temperatures are calculated using a finite difference approach based on the local contact pressure and the COF. With the local contact pressure and temperatures known, the local wear is determined by numerical integration of Archard's wear law. The plateau dynamics are modelled with a CA, and finally the wear emissions can be determined.

The CA approach described above includes determination of both the wear and temperature of both pad and disc. However, in the present paper the disc will not be considered (i.e., the disc will be regarded as a rigid body that does not wear). The temperatures of the pad and disc will also not be considered. The reason for these simplifications is to keep the focus of the present paper fixed on how the COF and the wear emissions vary for different factors during a relatively large number of brake events. Without these simplifications, 


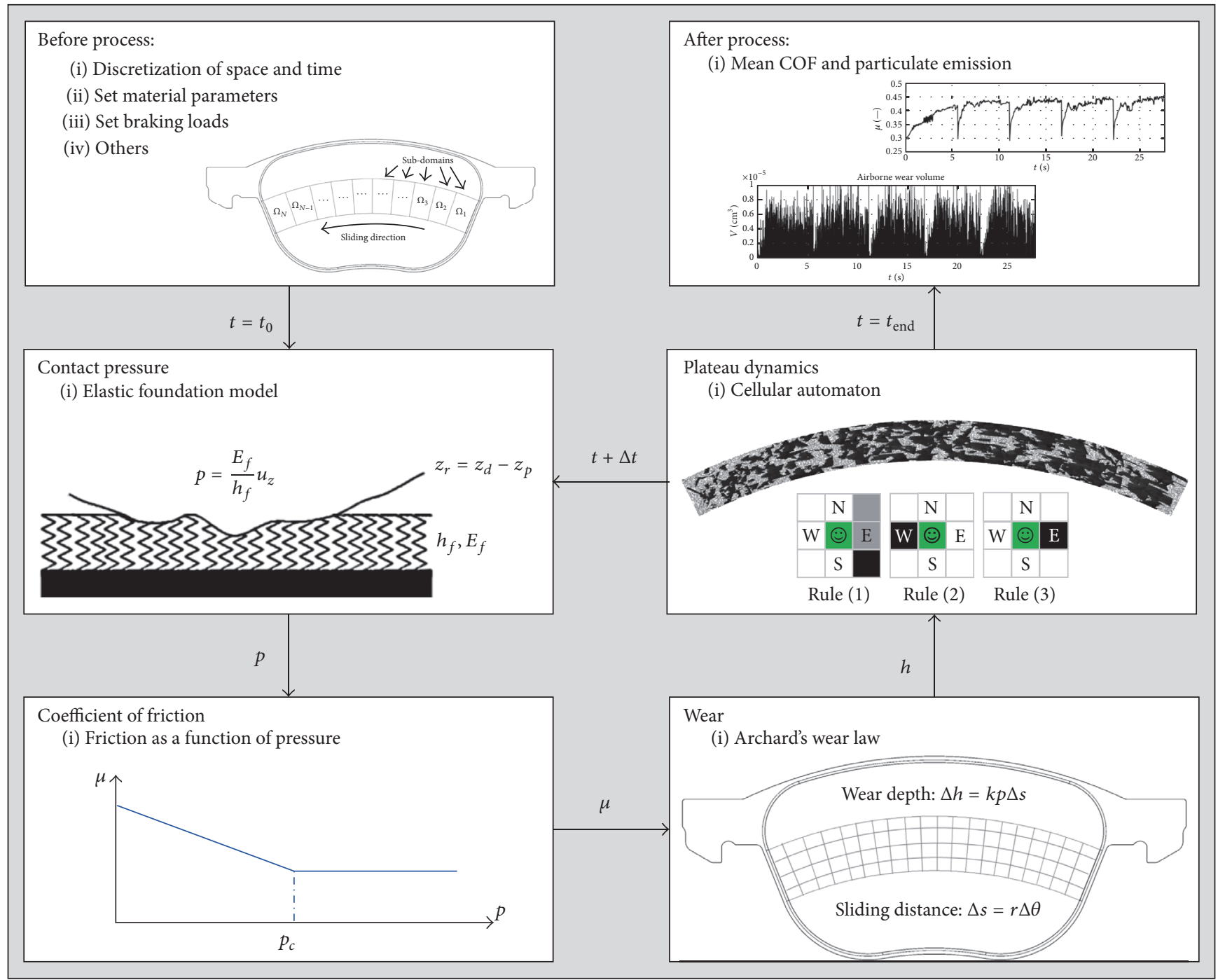

FIGURE 2: Simulation routine used in the simplified CA approach.

this focus would not be possible since the time steps need to be very short to ensure stability of both disc wear and temperature. A summary of the simplified CA approach without temperatures and disc wear follows and is illustrated in Figure 2.

In the preprocessing stage, the pad is discretized using a $2 \mathrm{D}$ mesh with polar coordinates that has $N_{\theta} \times N_{r}$ calculation points at $(\theta, r)=\left(i \times \Delta \theta, r_{i}+j \times \Delta r\right)$, where $\Delta \theta$ is the angular step; $\Delta r$ is the radial step; $i=1,2, \ldots ; N_{\theta}, j=1,2, \ldots, N_{r}$; and $r_{i}$ is the inner radius of the simulated domain of the total pad. Only a portion of the total pad surface is considered in the simulation. To decrease the computational time further, the simulated domain of the pad is divided into $N$ subdomains in the angular direction, each of which has $N_{m} \times N_{r}$ calculation points, where $N_{m}=N_{\theta} / N$. The division into subdomains is illustrated in Figure 3.

The time step $\Delta t$ is defined as the time it takes for one calculation point on the disc surface to pass through one subdomain on the pad surface. The time step is not constant during a brake event since the rotational speed of the rotor changes. The wear generated in subdomain $\Omega_{k}$ during $\Delta t$ will enter the next subdomain $\Omega_{k+1}$ in the following time step. The wear generated in subdomain $\Omega_{N}$ will be discharged into the surroundings in the following time step as wear emissions.

An elastic foundation model [14] is used to determine the local contact pressure, gap, and contact area of the pads and rotor. In this contact model, the contact is treated as a set of elastic bars that deform independently of each other. The elastic foundation is deformed by a rigid indenter that is defined by the gap between the pad and disc surfaces before they are deformed. When the normal load is applied, the rigid indenter is forced to move closer to the foundation until the sum of the local loads on each bar equal the normal load applied on the rigid indenter. No shear forces are considered in this contact model.

Friction in disc brakes is determined by the third body tribofilm formed at the pad-to-rotor interface (see, e.g., [15, 16]). Österle and Dmitriev [17] concluded that the COF 


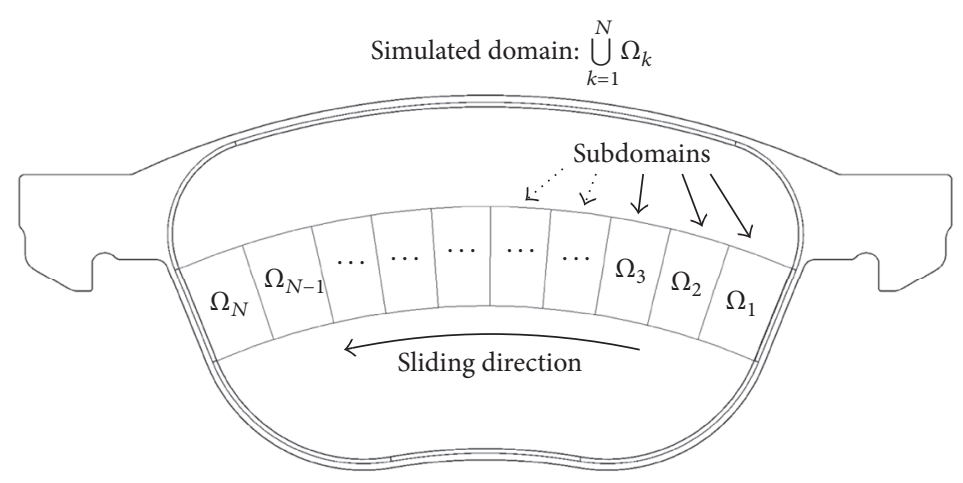

FIgURE 3: A schematic overview of the discretization of the pad.

of the tribofilm decreases almost linearly with increased contact pressure and that when the pressure reaches a certain critical value the COF will remain constant. This relation between $\mathrm{COF}$ and contact pressure could also be seen in POD tests conducted on a low metallic pad material [18]. In the present study the COF between the pad resin and the rotor is considered to be negligible compared to the COF between the contact plateaus and the disc. The COF between primary and secondary plateaus is assumed to be the same since the tribofilm covers both.

The wear depth of the contact plateaus is computed by numerical integration of Archard's wear law [19]. The specific wear rate of the pad friction material determined from POD experiments can be considered valid for the contact plateaus. When the resin of the pad is in contact with the rotor, it is assumed to wear down a certain amount immediately, leaving gaps in which the wear particles can flow.

The plateau dynamics are modelled using a CA as proposed by Wahlström et al. [8-10]. Seven rules were formulated to determine the plateau status (primary, secondary, or none) of each cell on the surface of the pad. These rules are based on POD studies [20,21] with composite pad materials running against glass discs which visually show by videorecording the growth and destruction of contact plateaus. Rules (1) to (3) deal with the creation of secondary plateaus. If a cell in the opposite direction to the wear particle flow (1) has one plateau neighbour to the east, (2) has one plateau neighbour to the east and one to the north-east or south-east, or (3) has one plateau neighbour to the east, one to the northeast, and one to the south-east, and if the wear volume is sufficient to fill the gap, the cell changes its status to secondary plateau.

Rules (4) and (5) deal with the destruction of secondary plateaus. If a cell of secondary plateau status (4) has fewer than one eastern neighbour or (5) wears down, it will change its status to none.

Rules (6) and (7) have been defined for the primary plateaus. If a cell of primary plateau status (6) has a height less than the minimum gap between the pad and disc surfaces or (7) wears down, it will change its status to none.

After the CA has been run, it is known how much of the wear volume leaves the last subuniverse into the surroundings as wear emissions.
TABle 1: Values of the four factors used as input data to the full factorial experiment.

\begin{tabular}{lcccc}
\hline Level & $S[-]$ & $\mathrm{WP}\left[\mathrm{m}^{3} / \mathrm{Nm}\right]$ & $\mathrm{WR}[\mathrm{m}]$ & $A[\%]$ \\
\hline- & 0 & $10^{-13}$ & $10^{-6}$ & 10 \\
0 & - & $10^{-14}$ & - & - \\
+ & 1 & $10^{-15}$ & $10^{-7}$ & 20 \\
\hline
\end{tabular}

\section{Factorial Design}

A full factorial design is undertaken to investigate the effects of different wear and fibre parameters of the pad friction material on the mean $\mathrm{COF}$ and the mean wear emissions. The mean COF (MU) and the mean wear emissions $(V)$ are defined as response variables. The stability of the secondary contact plateaus between brake events $(S)$, specific wear rate of the contact plateaus (WP), wear depth of the pad resin (WR), and metal fibre surface area fraction $(A)$ are chosen to be factors in the factorial design. The 2-level factor $S$ takes into account what happens to the secondary plateaus after a brake event when the braking load is zero. The high and low levels of $S$ correspond to the two extremes: $S-$ means all secondary plateaus remain on the pad surface; $S+$ means all secondary plateaus are removed from the pad surface between brake events. For the latter situation the secondary plateaus must be reformed in every brake event, which can be considered to be an in-stop increase of COF resulting in a peak in wear emission after the brake event. The factor WP has been defined as three levels since it could have a strong effect on both the COF and the wear emissions. $\mathrm{WP}+$ could correspond to a semimetallic [22], WP0 to a low metallic [23], and WP- to a nonasbestos organic pad friction material [24]. The two-level factor $R$ takes into account how the resin of the pad wears. $R+$ corresponds to the case when the contact temperature is high enough to decompose the resin to a deeper wear depth, while $R$ - corresponds to a more moderate contact temperature situation. The two-level factor $A$ is defined as the percentage of metal fibres at the contact surface that are stable enough to act as primary contact plateaus. Table 1 presents the chosen levels of the four factors. Table 2 shows the corresponding 24-run design matrix for the factorial experiment. 
TABLE 2: 24-run full design matrix with four factors.

\begin{tabular}{|c|c|c|c|c|}
\hline Test & $S$ & WP & WR & $\bar{A}$ \\
\hline 1 & - & - & - & - \\
\hline 2 & + & - & - & - \\
\hline 3 & - & 0 & - & - \\
\hline 4 & + & 0 & - & - \\
\hline 5 & - & + & - & - \\
\hline 6 & + & + & - & - \\
\hline 7 & - & - & + & - \\
\hline 8 & + & - & + & - \\
\hline 9 & - & 0 & + & - \\
\hline 10 & + & 0 & + & - \\
\hline 11 & - & + & + & - \\
\hline 12 & + & + & + & - \\
\hline 13 & - & - & - & + \\
\hline 14 & + & - & - & + \\
\hline 15 & - & 0 & - & + \\
\hline 16 & + & 0 & - & + \\
\hline 17 & - & + & - & + \\
\hline 18 & + & + & - & + \\
\hline 19 & - & - & + & + \\
\hline 20 & + & - & + & + \\
\hline 21 & - & 0 & + & + \\
\hline 22 & + & 0 & + & + \\
\hline 23 & - & + & + & + \\
\hline 24 & + & + & + & + \\
\hline
\end{tabular}

TABLE 3: Drive cycle used in the simulation.

\begin{tabular}{lccccc}
\hline$\#$ & Block & Initial speed $[\mathrm{km} / \mathrm{h}]$ & Final speed $[\mathrm{km} / \mathrm{h}]$ & Deceleration $[\mathrm{g}]$ & Number of stops [\#] \\
\hline 1 & Burnish & 50 & 4 & 0.25 & 50 \\
2 & Town block \#1 & 50 & 4 & 0.25 & 20 \\
3 & Highway block \#1 & 150 & 80 & 0.4 & 10 \\
4 & Country road block \#1 & 80 & 4 & 0.35 & 20 \\
5 & Country road block \#2 & 100 & 4 & 0.4 & 20 \\
6 & Highway block \#2 & 180 & 40 & 0.5 & 5 \\
7 & Town block \#2 & 50 & 4 & 0.25 & 20 \\
8 & County road block \#3 & 100 & 4 & 0.4 & 5 \\
9 & Hill descent block & 80 & & 0.35 &
\end{tabular}

TABLE 4: Data of car and brake system used in the simulation.

\begin{tabular}{lc}
\hline Front wheel load & $690 \mathrm{~kg}$ \\
Wheel radius & $314 \mathrm{~mm}$ \\
Disc outer radius & $139 \mathrm{~mm}$ \\
Disc inner radius & $80 \mathrm{~mm}$ \\
Disc effective radius & $113 \mathrm{~mm}$ \\
Pad area & $5080 \mathrm{~mm}^{2}$ \\
Cylinder diameter & $57 \mathrm{~mm}$ \\
\hline
\end{tabular}

\section{Simulation Input Parameters}

Besides the design variables, the simulation requires a number of other input parameters. The simulation used the running conditions from the dynamometer bench running cycle (Table 3) created by Perricone et al. [13] to study particulate emissions from disc brakes. This cycle is a reduced
TABLE 5: Discretization parameters used in the simulation.

\begin{tabular}{lc}
\hline Angular step, $\Delta \theta$ & $0.044^{\circ}$ \\
Radial step, $\Delta r$ & $100 \mu \mathrm{m}$ \\
Angular points, $N_{\theta}$ & 1000 \\
Radial points, $N_{r}$ & 201 \\
Subdomains, $N$ & 10 \\
\hline
\end{tabular}

version of the SAE J2707 Method B block wear cycle [25], which is used to study wear of brakes. The deceleration is kept constant during braking by measuring the brake torque and controlling the applied normal load. Data from a typical medium-sized car equipped with single piston sliding callipers on the front wheels is used as input to the simulation (Table 4).

The discretization parameters used in the simulation are seen in Table 5. The parameters correspond to simulating the 


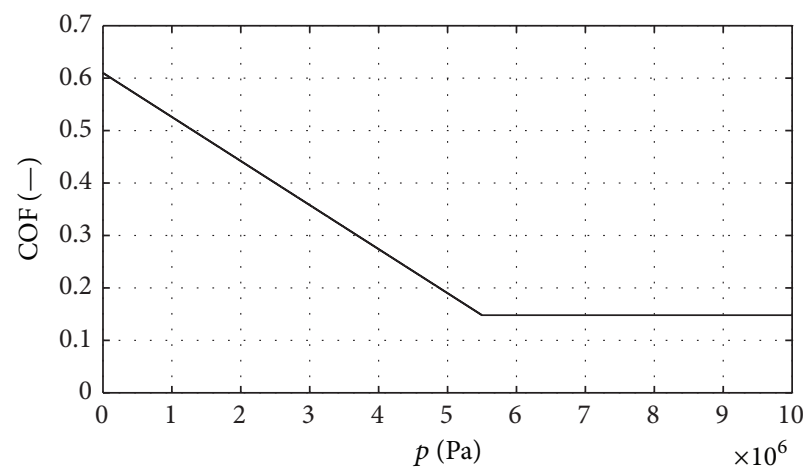

FIGURE 4: Local COF as a function of contact pressure.

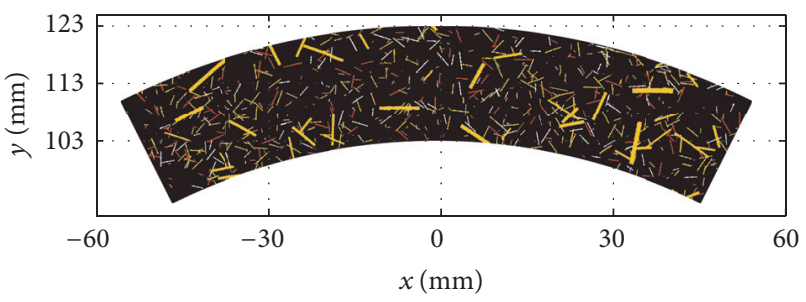

(a)

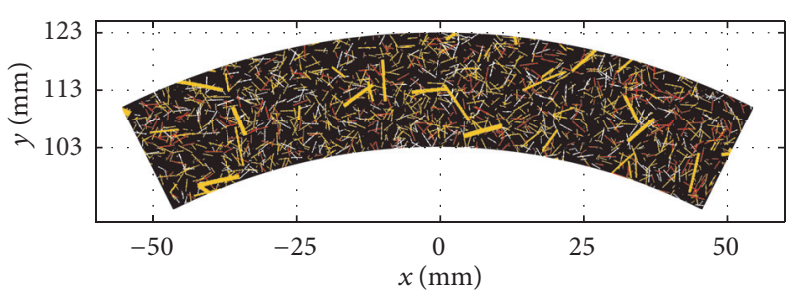

(b)

Figure 5: (a): Metal fibre distribution used in the simulation for $A-$. (b) Metal fibre distribution used in the simulation for $A+$.

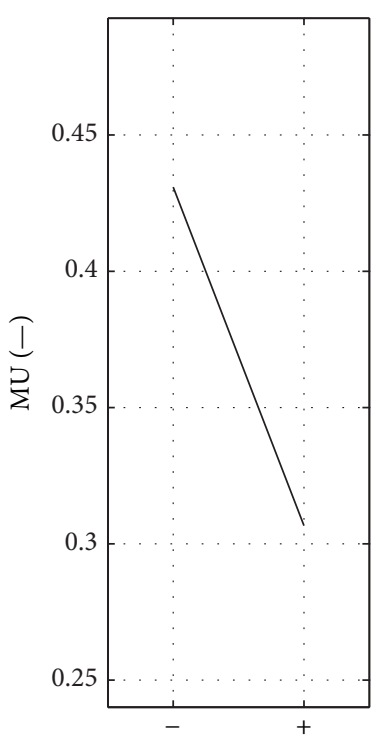

$S$
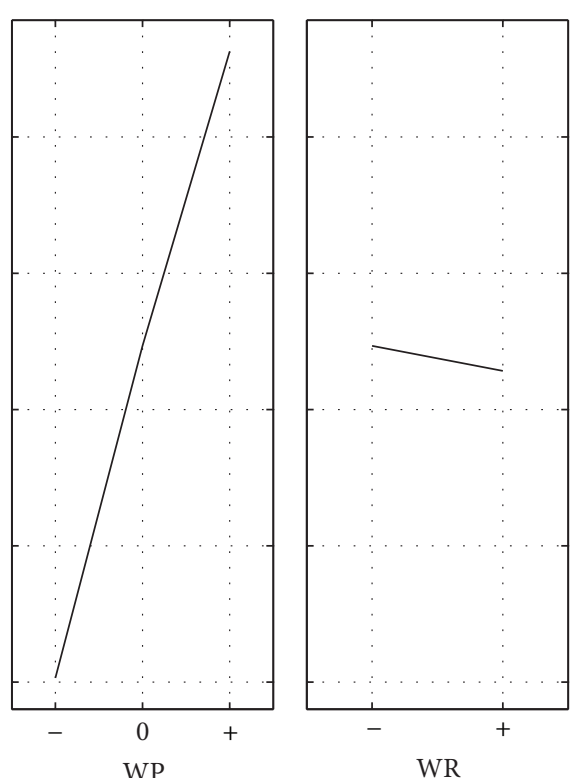

WR

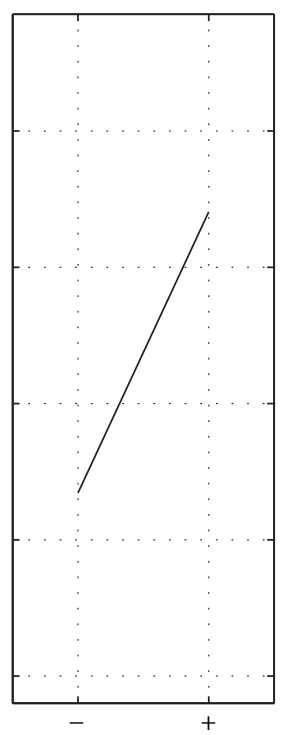

A

Figure 6: Effect plots of factors $S$, WP, WR, and $A$ for the response COF.

whole pad in the angular direction and $20 \mathrm{~mm}$ in the radial direction. The simulated areas represent up to $40 \%$ of the total pad area.

The COF-pressure function described by Wahlström [8] was used. The local COF linearly decreases with the local contact pressure; however, the lowest possible COF was set to 0.15 (Figure 4 ).

The metal fibres are set to $10 \%$ and $20 \%$ of the total initial pad surface area for $A$ - and $A+$, respectively (Figure 5 ). The fibres are all treated as having the same physical properties. The lengths of the fibres are $1-10 \mathrm{~mm}$ and their diameters
$200-700 \mu \mathrm{m}$. The orientations of the generated fibres were distributed randomly and their heights were distributed according to the diameters mentioned above. The simulated roughness of the resin material is uniformly distributed between 0 and $100 \mu \mathrm{m}$.

\section{Results and Discussion}

The effect plots of the design variables and the response variable MU are presented in Figure 6. The corresponding interaction plot is presented in Figure 7. A change in the 

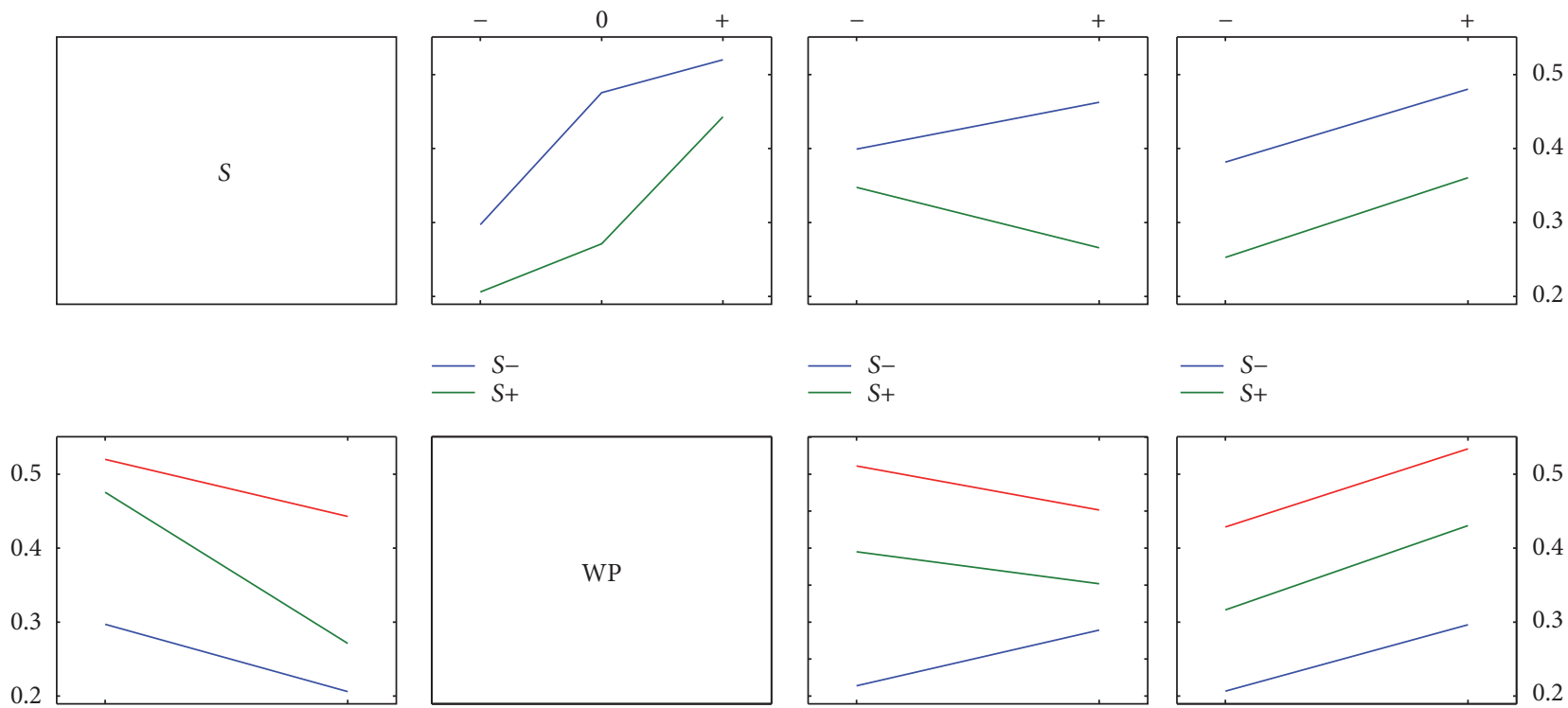

$-S$

$-S-$
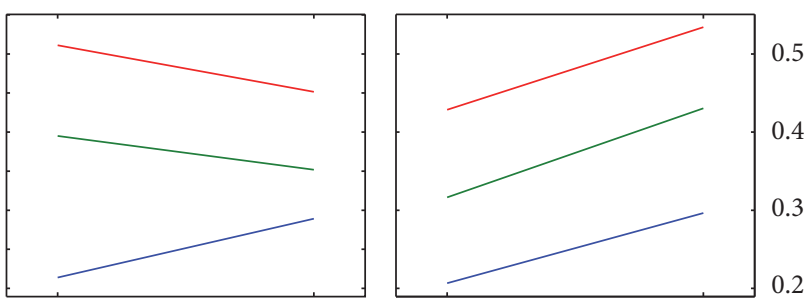

$$
\begin{aligned}
& \text { WP- } \\
& \text { WP0 } \\
& - \text { WP+ }
\end{aligned}
$$
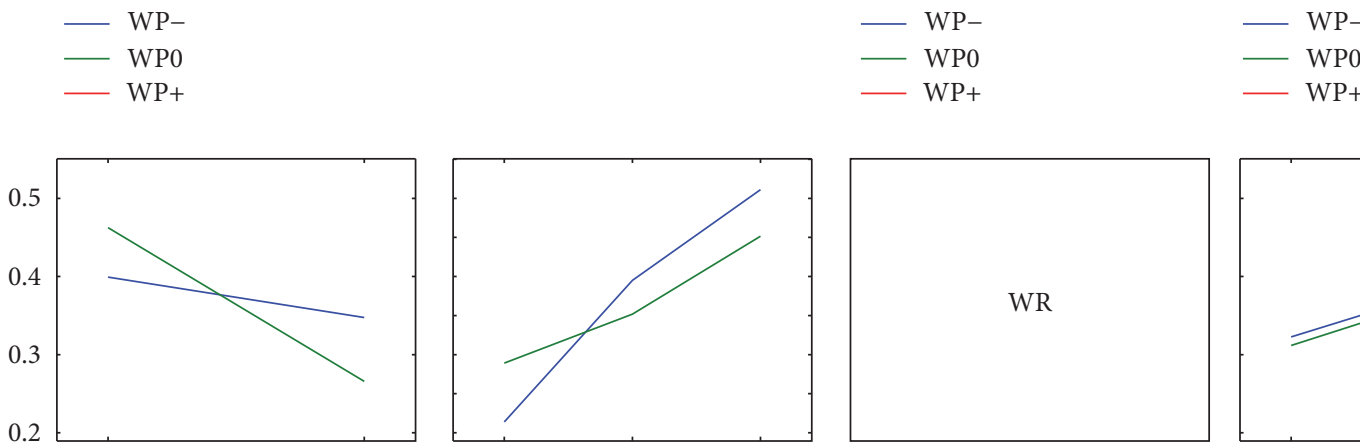

- WP
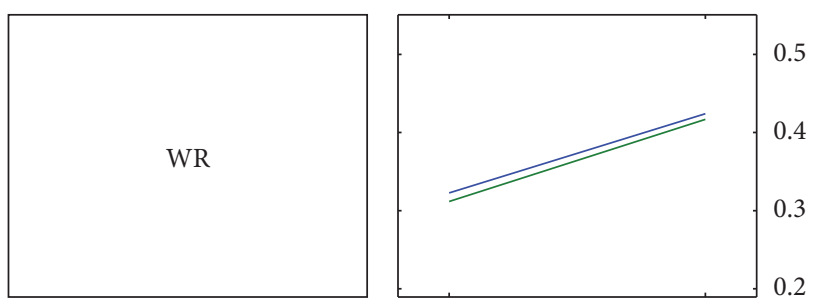

- WR-

- WR-

- WR+
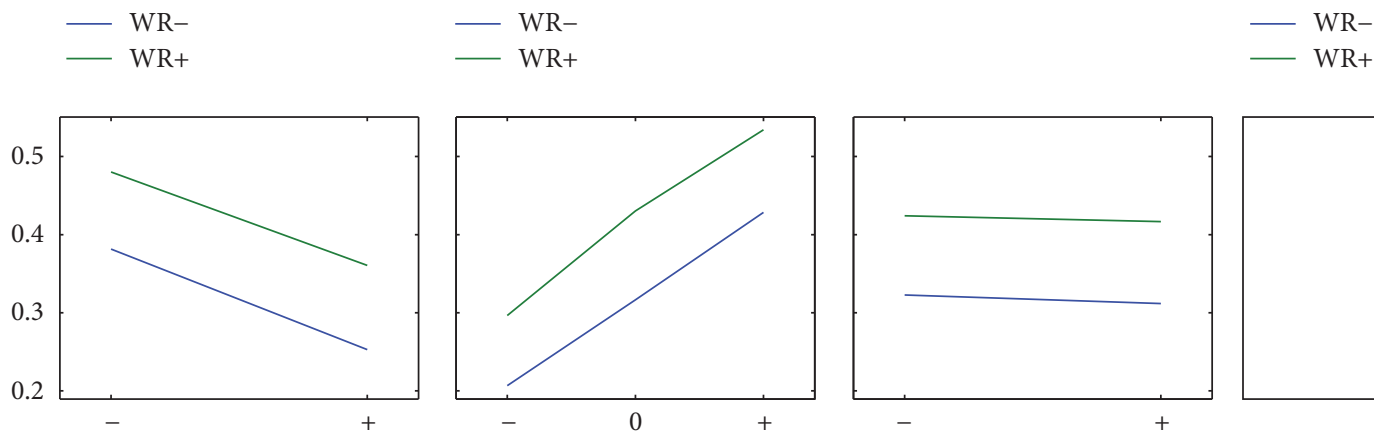

$-A-$

$-A+$
A-

$-A+$
A-

FIGURE 7: Interaction plots of the factors interaction of the response COF.

design variable WP has the strongest effect on MU, while the factor WR has the weakest effect. This means that even if the wear depth of the resin is increased by a factor 10, the amount of wear is enough to fill the gap between the pad and the disc. As a result the contact area will be about the same. The three other design variables have a strong effect on MU, which means that changing them will affect the contact area and, in turn, the contact pressure. The only interactions that can be observed in Figure 7 are between the factor WR and the factors $S$ and WP. Note that the effect on MU seems to be linear with respect to factor WP; this could mean that using three levels was not necessary if the aim was to study only MU.

The effect plots of design variables and the response variable $V$ are presented in Figure 8, and the interaction plots are presented in Figure 9. As in the case of MU, the factor WP also has the strongest effect on the response variable $V$. This seems reasonable since the specific wear rate of the plateaus 

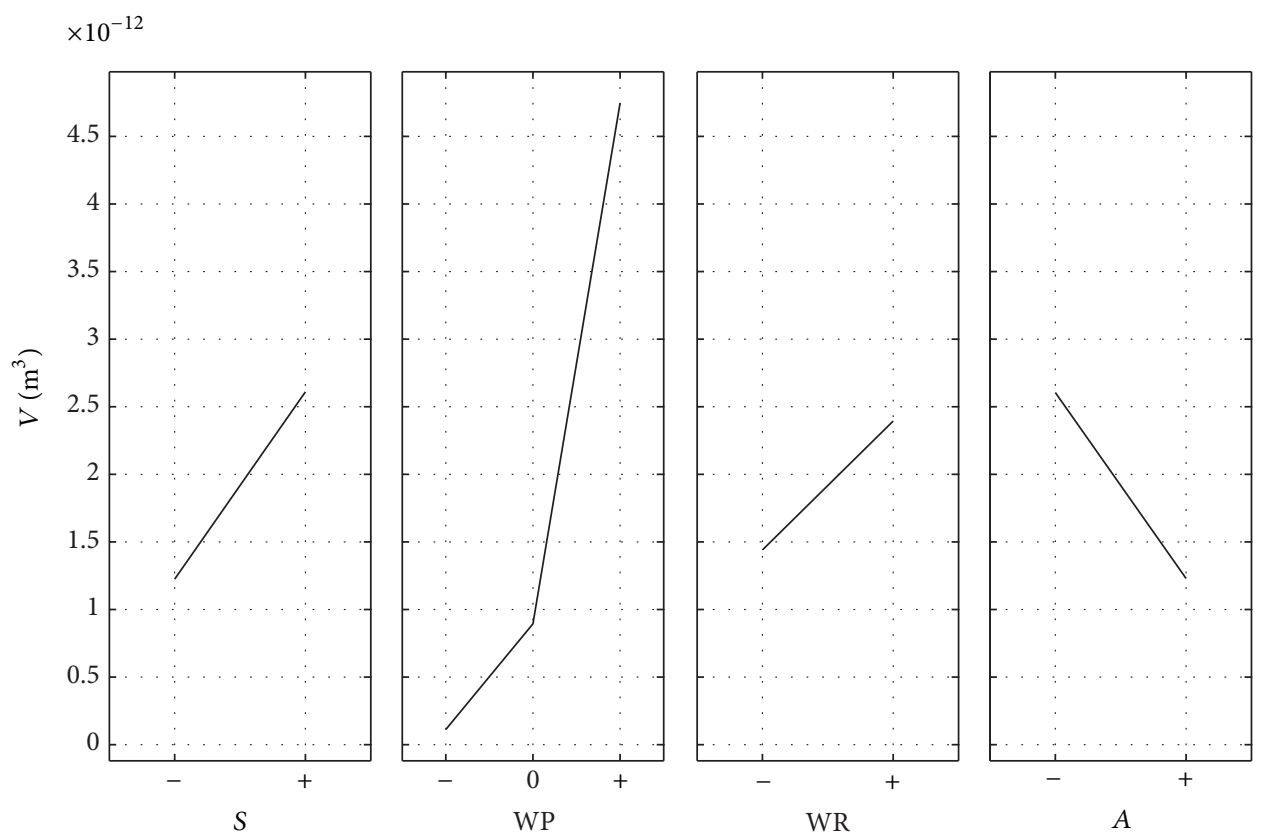

FIGURE 8: Effect plots of factors $S$, WP, WR, and $A$ of the response $V$.

directly affects the total wear of the pad. In contrast to $\mathrm{MU}$, the factor WR has a significant effect on $V$. It seems that the threelevel variable was necessary to be able to see the nonlinear effect of factor WP on the response PM. Above WP0 the wear emissions increase drastically. This could be because the amount of wear is more than enough to create secondary plateaus, and wear particles will instead leave the contact. Note that no interactions between the design variables can be observed in Figure 9.

The simulated MU for the whole test cycle is presented in Figure 10. The simulated mean wear volume that leaves the contact during the test cycle is presented in Figure 11.

In Figure 10 it can be seen that the MU in test runs 2, 8, and 10 remains at the lowest level of COF of 0.15 for the whole test cycle. This means that almost no secondary plateaus were formed during these runs and therefore these combinations of factors are not meaningful for further studies.

By observing Figures 6 and 10 it seems that a stable third body ( $S-$ ), a high specific wear (WP+), and a relatively high amount of metal fibres $(A+)$ give a relatively high and stable MU.

It can be seen in Figure 8 that a stable third body $(S-)$, a low specific wear (WP-), stable resin (WR-), and a relatively high amount of metal fibres $(A+)$ are associated with a low wear rate. This means that a high specific wear rate is good for obtaining a stable and relatively high COF but not good for keeping wear emissions down. For example, the lowest amount of wear emissions corresponds to run 13 but, as can be seen in Figure 10, the MU is too low to be useful in real applications. This is also the case for runs 1, 2, 7, and 14, which also have relatively low wear emission (Figures 10 and 11). Run 19, which has a low wear emission and a relatively acceptable MU, seems to be a good candidate for further investigations. It is not easy to draw any direct conclusions about the relationship between MU and $V$ from Figures 10 and 11.

Contact conditions that give a large fraction of the pad surface to be covered by contact plateaus result in a higher friction due to the assumed pressure dependence of the friction. The larger area results in a lower pressure which is associated with a high friction level. Furthermore, if the secondary plateaus are not lost when releasing the brake, the friction will keep more stable, since no time is required to reform them on the subsequent braking. The retained surface structure will offer the low-pressure situation from first contact. Naturally, all factors keeping the wear rate of the pad low (stable secondary plateaus, low specific wear, stable resin, and high amount of metal fibres) also result in low wear emissions. Under conditions where a large part of all secondary plateaus is lost between brake events and the wear rate is very low, it will take longer time to form new secondary plateaus, which result in longer time for the high friction situation to establish.

\section{Conclusion}

This paper presents a factorial design developed using a cellular automaton approach to study the effect of the wear parameters of the pad friction material on the mean coefficient of friction and mean wear emissions. The results of the simulation indicate that a stable third body, a high specific wear, and a relatively high amount of metal fibres result in a high and stable mean COF. A stable third body, a low specific wear, a stable resin, and a relatively high amount of metal fibres result in low wear emissions. There is a trade-off that depends on the specific wear rate of the contact plateaus 

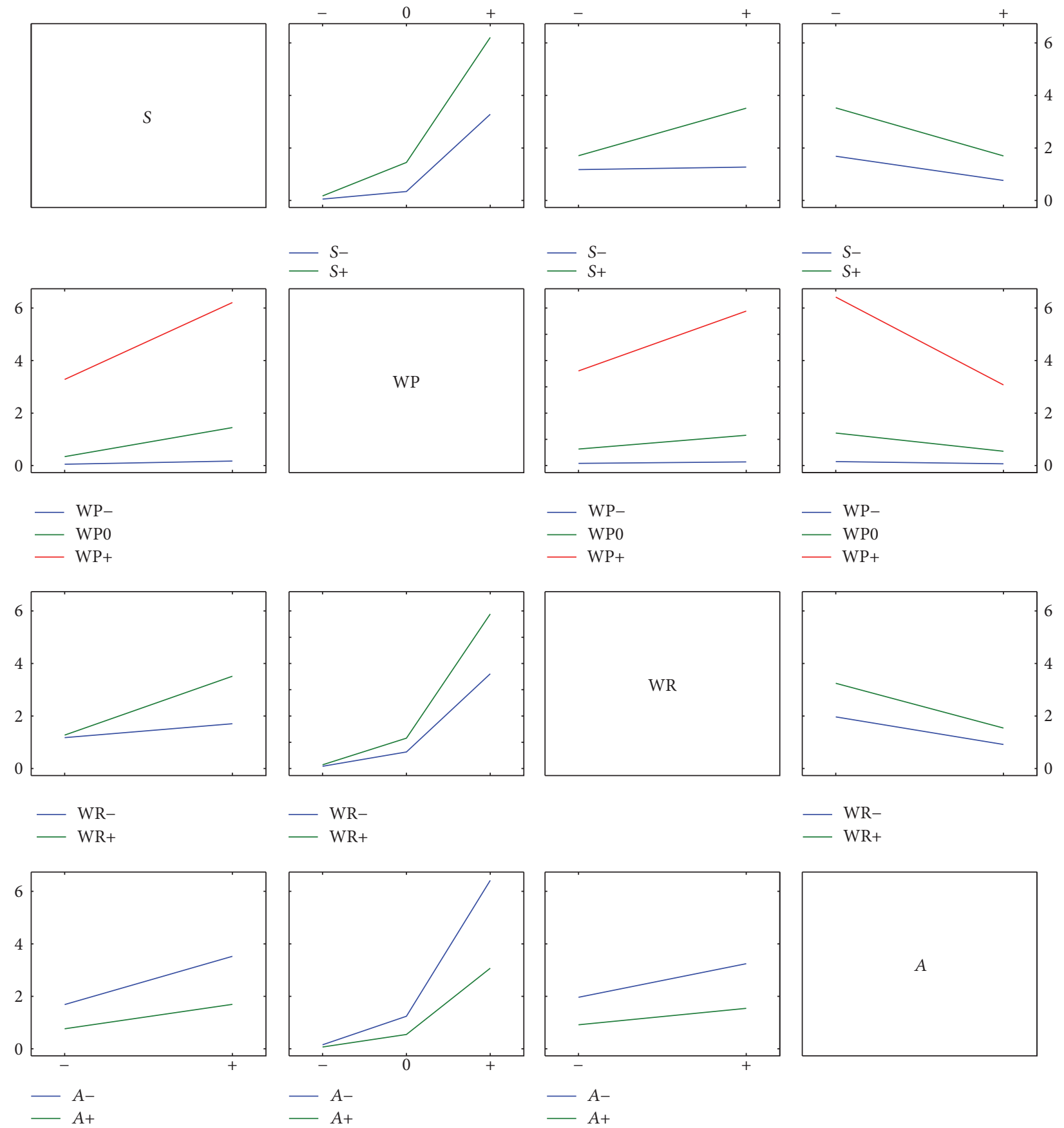

FIGURE 9: Interaction plots of the factors interaction of the response $V$.

between obtaining a sufficiently high stable friction and low wear emissions.

\section{Abbreviations}

COF: Coefficient of friction

CA: Cellular automaton

POD: Pin-on-disc tribometer

PM: Particulate matter.

\section{Competing Interests}

The author declares that there are no competing interests.

\section{Acknowledgments}

The research leading to these results received funding from the European Union's Horizon 2020 research and innovation programme under Grant Agreement no. 636592. 


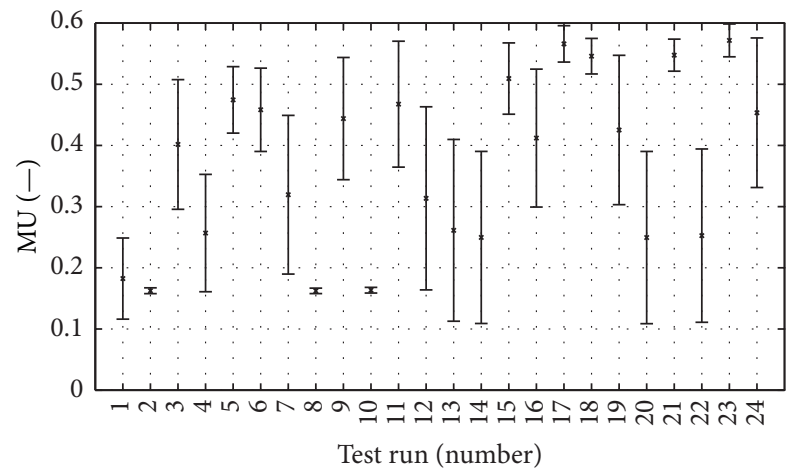

FIgURE 10: Simulated MU for the 24 runs during the whole cycle.

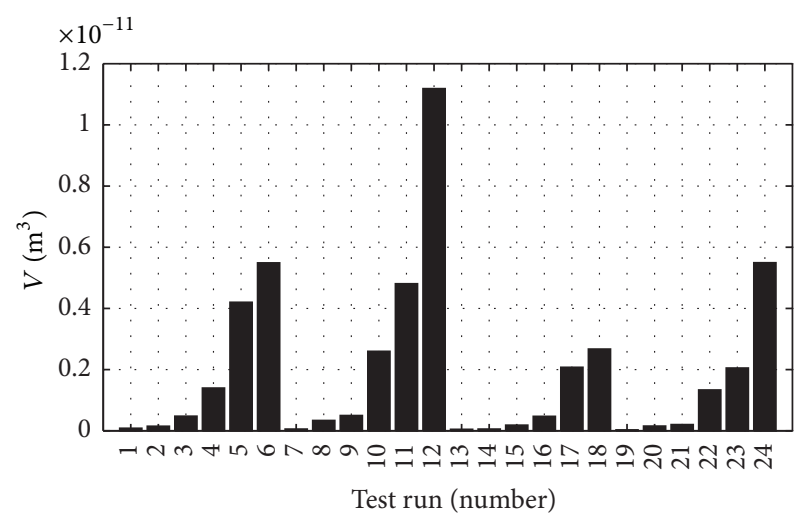

FIgURE 11: Mean wear volume $(V)$ that leaves the contact for the 24 runs.

\section{References}

[1] X. Querol, M. Viana, A. Alastuey et al., "Source origin of trace elements in PM from regional background, urban and industrial sites of Spain," Atmospheric Environment, vol. 41, no. 34, pp. 7219-7231, 2007.

[2] A. Escrig, E. Monfort, I. Celades et al., "Application of optimally scaled target factor analysis for assessing source contribution of ambient $\mathrm{PM}_{10}$," Journal of the Air \& Waste Management Association, vol. 59, no. 11, pp. 1296-1307, 2009.

[3] T. Grigoratos and G. Martini, "Brake wear particle emissions: a review," Environmental Science and Pollution Research, vol. 22, no. 4, pp. 2491-2504, 2015.

[4] R. M. Harrison, A. M. Jones, J. Gietl, J. Yin, and D. C. Green, "Estimation of the contributions of brake dust, tire wear, and resuspension to nonexhaust traffic particles derived from atmospheric measurements," Environmental Science and Technology, vol. 46, no. 12, pp. 6523-6529, 2012.

[5] M. Eriksson, F. Bergman, and S. Jacobson, "On the nature of tribological contact in automotive brakes," Wear, vol. 252, no. 1-2, pp. 26-36, 2002.

[6] W. Österle, M. Griepentrog, T. Gross, and I. Urban, "Chemical and microstructural changes induced by friction and wear of brakes," Wear, vol. 250-251, no. 2, pp. 1469-1476, 2001.

[7] M. Müller and G. P. Ostermeyer, "A cellular automaton model to describe the three-dimensional friction and wear mechanism of brake systems," Wear, vol. 263, no. 7-12, pp. 1175-1188, 2007.
[8] J. Wahlström, "A comparison of measured and simulated friction, wear, and particle emission of disc brakes," Tribology International, vol. 92, pp. 503-511, 2015.

[9] J. Wahlström, A. Söderberg, and U. Olofsson, "A cellular automaton approach to numerically simulate the contact situation in disc brakes," Tribology Letters, vol. 42, no. 3, pp. 253-262, 2011.

[10] J. Wahlström, "Towards a cellular automaton to simulate friction, wear, and particle emission of disc brakes," Wear, vol. 313, no. 1-2, pp. 75-82, 2014.

[11] J. Wahlström, A. Söderberg, and U. Olofsson, "Simulation of airborne particles from disc brakes," SAE Technical Paper 013040, 2009.

[12] J. Wahlström, A. Söderberg, L. Olander, A. Jansson, and U. Olofsson, "A pin-on-disc simulation of airborne wear particles from disc brakes," Wear, vol. 268, no. 5-6, pp. 763-769, 2010.

[13] G. Perricone, J. Wahlström, and U. Olofsson, "Towards a test stand for standardized measurements of the brake emissions," Proceedings of the Institution of Mechanical Engineers, Part D: Journal of Automobile Engineering, vol. 230, no. 11, pp. 1521-1528, 2016.

[14] A. Söderberg and S. Björklund, "Validation of a simplified numerical contact model," Tribology International, vol. 41, no. 9-10, pp. 926-933, 2008.

[15] W. Österle and I. Urban, "Friction layers and friction films on PMC brake pads," Wear, vol. 257, no. 1-2, pp. 215-226, 2004.

[16] W. Österle and I. Urban, "Third body formation on brake pads and rotors," Tribology International, vol. 39, no. 5, pp. 401-408, 2006.

[17] W. Österle and A. I. Dmitriev, "Functionality of conventional brake friction materials-perceptions from findings observed at different length scales," Wear, vol. 271, no. 9-10, pp. 2198-2207, 2011.

[18] M. Alemani, U. Olofsson, G. Perricone, A. Söderberg, J. Wahlström, and A. Ciotti, "A study on the load level influence on particulate matter emissions from the sliding contact between a low steel friction material and cast iron," in Proceedings of the EuroBrake, Paper EB2015-FMC-004, Dredsen, Germany, May 2015.

[19] J. F. Archard, "Contact and rubbing of flat surfaces," Journal of Applied Physics, vol. 24, no. 8, pp. 981-988, 1953.

[20] M. Eriksson, J. Lord, and S. Jacobson, "Wear and contact conditions of brake pads: dynamical in situ studies of pads on glass," Wear, vol. 249, no. 3-4, pp. 272-278, 2001.

[21] S. Gramstadt, Methoden der in-situ Visualisierung der Reibzonendynamik trockenlaufender Reibpaarungen unter Ergänzung physikalischer und chemischer Charakterisierungen der Reibpartner [Ph.D. thesis], Universitätsverlag Ilmenau, Ilmenau, Germany, 2015.

[22] G. Straffelini and L. Maines, "The relationship between wear of semimetallic friction materials and pearlitic cast iron in dry sliding," Wear, vol. 307, no. 1-2, pp. 75-80, 2013.

[23] P. C. Verma, R. Ciudin, A. Bonfanti, P. Aswath, G. Straffelini, and S. Gialanella, "Role of the friction layer in the hightemperature pin-on-disc study of a brake material," Wear, vol. 346-347, pp. 56-65, 2016.

[24] P. C. Verma, L. Menapace, A. Bonfanti, R. Ciudin, S. Gialanella, and G. Straffelini, "Braking pad-disc system: wear mechanisms and formation of wear fragments," Wear, vol. 322-323, pp. 251258, 2015.

[25] SAE J2707, Wear Test Procedure on Inertia Dynamometer for Brake Friction Materials, SAE International, 2005. 


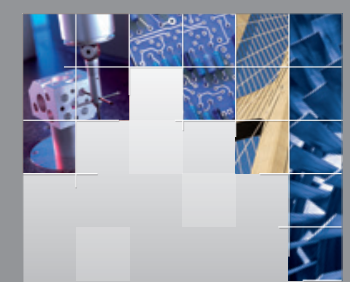

\section{Enfincering}
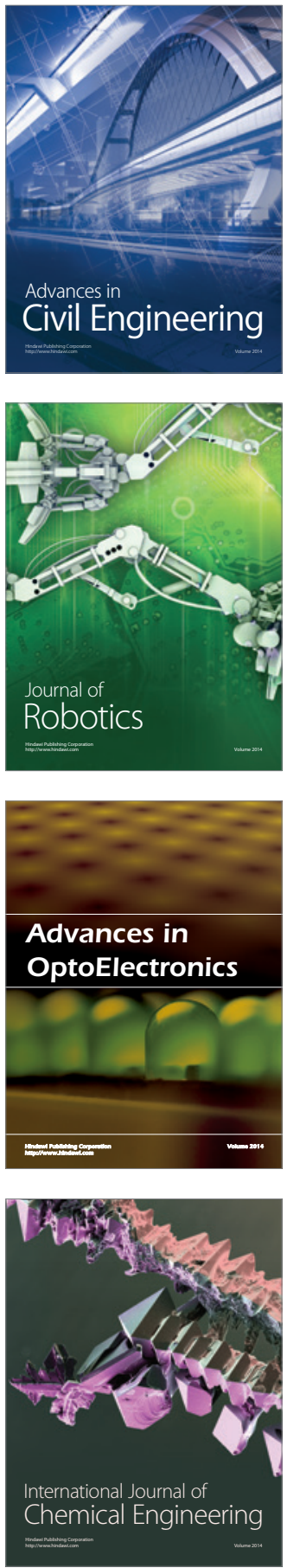

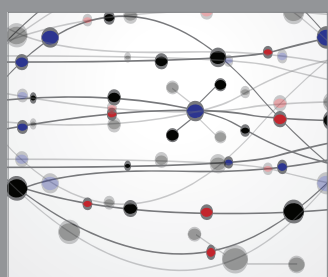

The Scientific World Journal

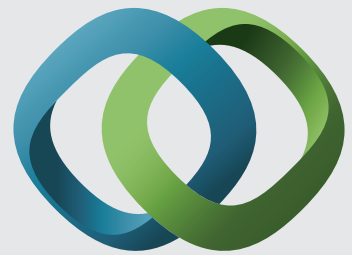

\section{Hindawi}

Submit your manuscripts at

http://www.hindawi.com
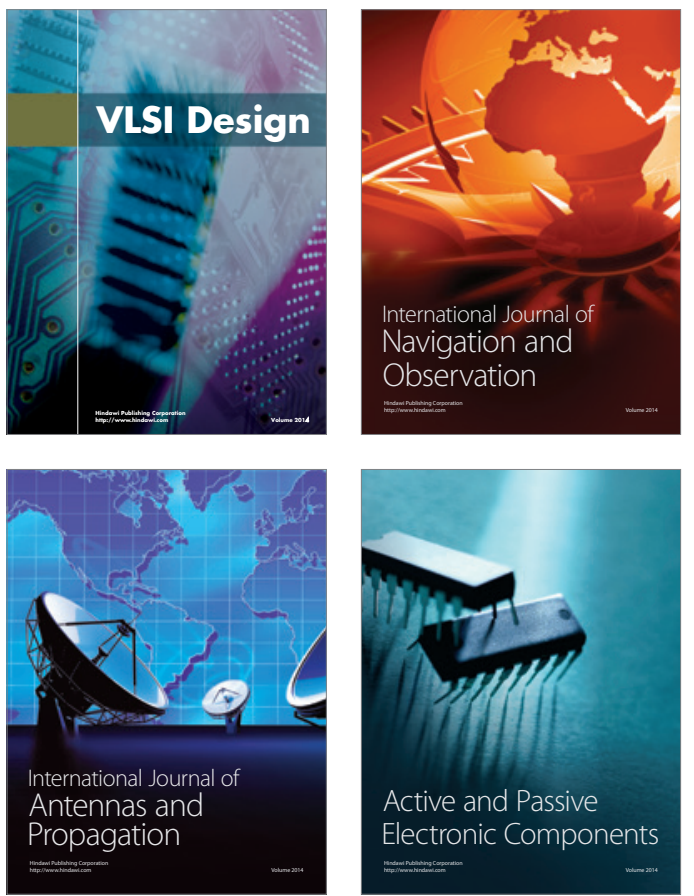
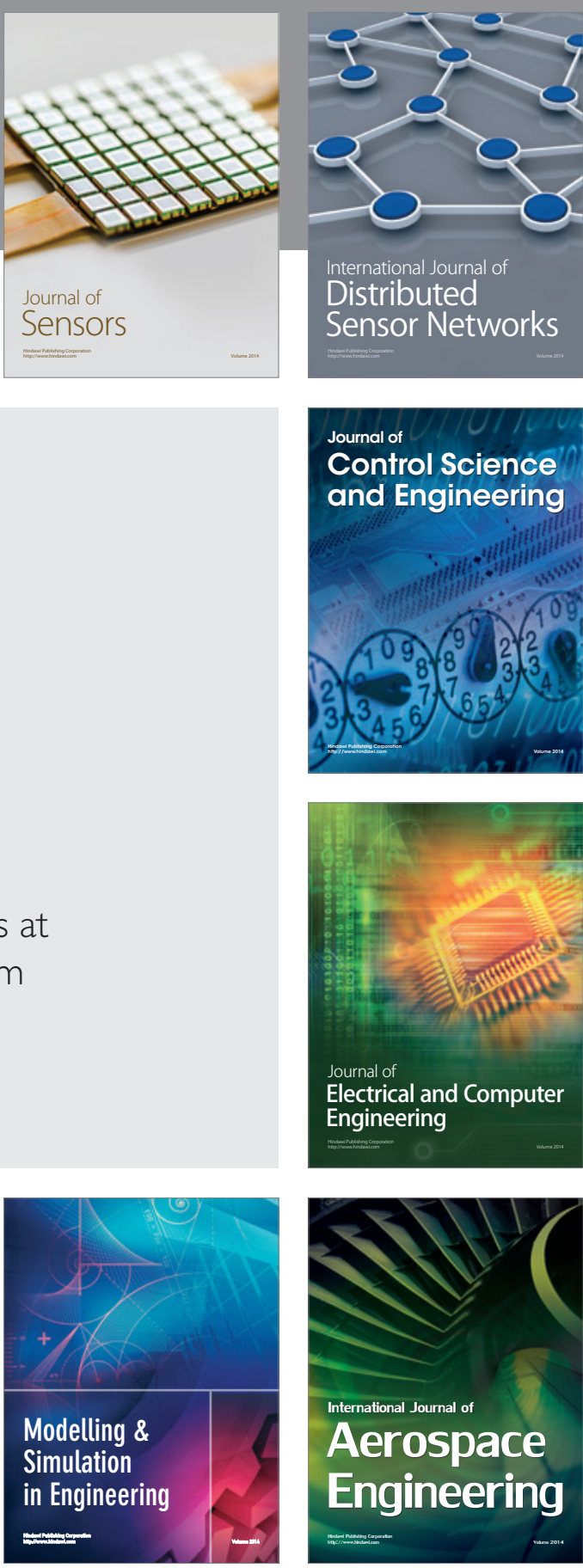

International Journal of

Distributed

Sensor Networks

Journal of

Control Science

and Engineering
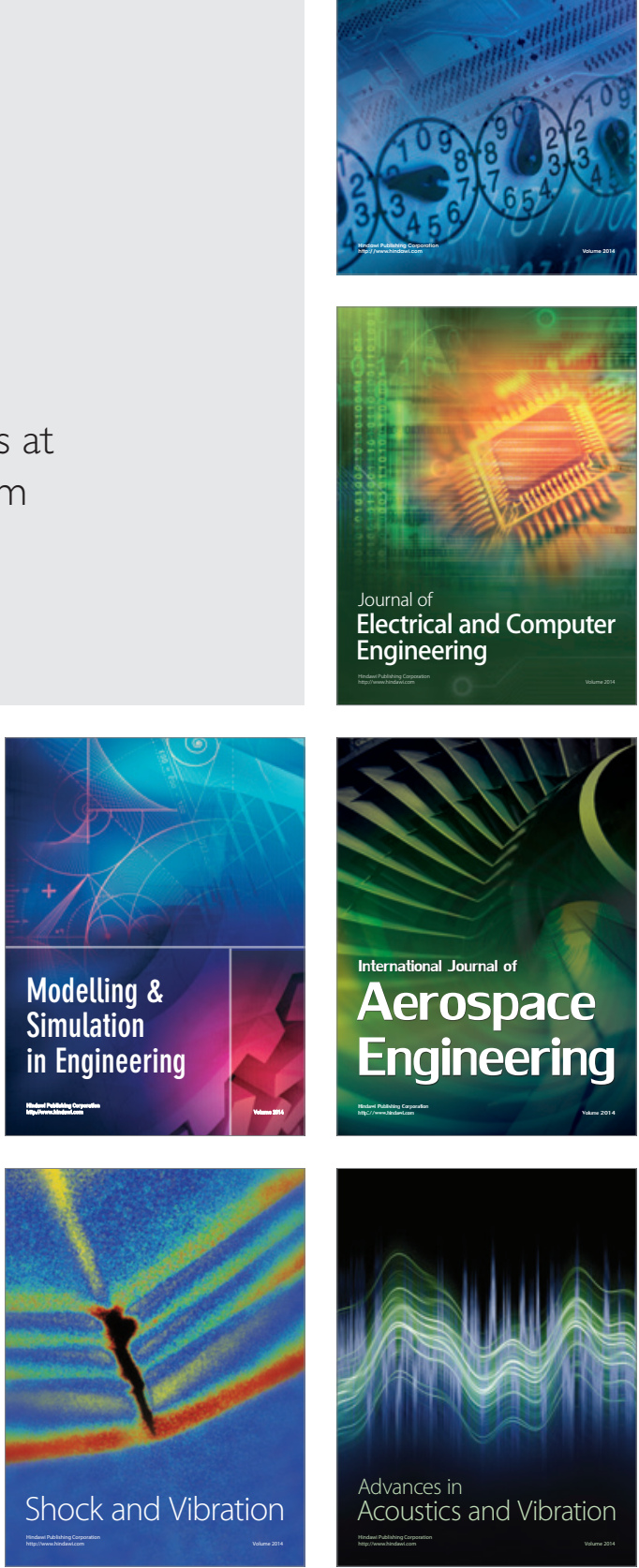